\title{
Long Term Growth of Factor-Producing Lymphoid and Myeloid Cells in Serum-Free Medium
}

\author{
Yasuo Tanno ${ }^{1}$ and Judah A. Denburg ${ }^{2}$ \\ ${ }^{1}$ The First Department of Internal Medicine, Tohoku University, School of \\ Medicine, Sendai 980, Japan, ${ }^{2}$ Departments of Pathology and Medicine, Mc- \\ Master University, Hamilton, Ontario, Canada
}

\begin{abstract}
The ability to grow lymphoid and myeloid cells in serum-free culture medium allows researchers to analyze the factors and mechanisms required for hemopoietic cell growth and differentiation without the interference of undefined serum components. Therefore, we used a serum-free medium, RITC 55-9 that consisted of modified Dulbecco's MEM supplemented with bovine serum albumin (BSA), transferrin (Tf) and insulin (Ins) to culture human T lymphoid (Mo), murine myelomonocytoid (WEHI-3B) and murine interleukin (IL)-3-dependent (32Dcl/H4) cell lines. Mo was maintained in RITC for more than 8 months and had a mean viability of $59 \%$ and the same doubling times as in serum-containing medium (SCM).

Under these conditions, Mo cells produced hemopoietic colony-stimulating activity that included production of a basophil/eosinophil differentiation factor of similar content to that produced in SCM. WEHI-3B cells grown for more than 12 months in RITC, or for more than 3 months in RITC without Tf and Ins, had a doubling time of $20 \mathrm{~h}$, whereas cells maintained in protein-free RITC showed a 2-fold increase in doubling time then died within 3 months. The IL-3 production by WEHI-3B cells cultured in RITC was higher than the production by cells grown in SCM. When IL-3 was assayed in 32Dcl/H4 cells that had been maintained in RITC for more than 4 months, a lower response to IL-3 was found, an indication that components other than the BSA, Tf and Ins in fetal calf serum are required for optimal cell growth and differentiation.
\end{abstract}

In general, cells in culture require serum as the source of growth-supporting components as well as a rich nutrient media (8). The use of serum, however, introduces such uncontrollable variables as different sources, lots and concentration, which may produce variability in the experimental results, there by raising a major technical difficulty in the analysis of the factors and mechanisms required for cell growth and differentiation. Several serum-free culture systems have been developed that

Abbreviations used: BaGPA, basophil growth-promoting activity; BSA, bovine serum albumin; CM, conditioned medium; CSF, colony stimulating factor; Eo, eosinophil; EoGPA, eosinophil growth-promoting activity; FCS, fetal calf serum; GM, neutrophil-macrophage; IL-3, interleukin-3; IMDM, Iscove's modified Dulbecco's medium; Ins, insulin; SCM, serum-containing medium; Tf, transferrin; 2ME, 2-mercaptoethanol. 
circumvent these problems when culturing human lymphoid $(1,3,4,15,17,21,24)$, erythroleukemic $(14,23)$, promyelocytic $(2,20)$ and murine lymphoid $(11,13)$ cell lines as well as murine bone marrow cells $(6,10,12,19)$.

We previously reported the development of a serum-free medium which supports the growth of human B lymphocytes that are stimulated by pokeweed mitogen to produce immunoglobulines (21). We have report the use of this medium (RITC 55-9) to culture human $\mathrm{T}$ cell leukemic, murine myelomonocytic and murine interleukin-3dependent (IL-3) cell lines.

\section{MATERIALS AND METHODS}

Cell lines. The T lymphocytic leukemia cell line, Mo (7), was provided by Dr. David W. Golde of the University of California at Los Angels, CA, and the murine IL-3-dependent cell line, $32 \mathrm{Dcl} / \mathrm{H} 4$ (18), by Dr. Beda M. Stadler of the University of Bern, Switzerland. The murine myelomonocytic cell line, WEHI-3B (25) has been stocked in liquid nitrogen in our laboratory, since it was obtained from Dr. John Garland (Manchester, U.K.).

Culture media. The Basic powdered culture medium, RITC 55-9 (21), and the supplement vial containing $10 \mu \mathrm{g}$ bovine insulin (Ins; Sigma Chemical Co., St. Louis, MO) and $5 \mu \mathrm{g}$ human transferrin (Tf; Sigma) were supplied by Nissui Pharmaceutical Co., Tokyo. The basic powdered medium (11 g) was dissolved in 1 liter deionized distilled water, supplemented with $5 \mathrm{~g}$ bovine serum albumin (BSA; Cohn fraction V, Cat. No. A-2153 Sigma), $1.5 \mathrm{mg} \beta$-glycerophosphate (Sigma) and $1.3 \mathrm{mg}$ sodium bicarbonate (Baker Chemical Co., Phillipsburg, NJ), together with the supplement (10 $\mu \mathrm{g}$ Ins and $5 \mu \mathrm{g}$ Tf). This solution was sterilized using Sterivax-GS $(0.22 \mu \mathrm{m})$ (Millipore, Bedford, MA). Isocove's modified Dulbecco's medium (IMDM, Grand Island Biological Co., Grand Island, NY) was used in some experiments for comparison. McCoy's 5A medium (GIBCO) supplemented with $15 \%$ heat-inactivated fetal calf serum (FCS, GIBCO) and RPMI 1640 (GIBCO) with 10\% FCS were the standard serum-containing media used. All media were supplemented with $100 \mathrm{U} / \mathrm{mg}$ penicillin and $100 \mu \mathrm{g} / \mathrm{ml}$ streptomycin (GIBCO).

Cell cultures. Cells usually were cultured in $25 \mathrm{~cm}^{2}$ tissue culture flasks (3013, Falcon Labware, Oxnard, $\mathrm{CA}$ ) at $37^{\circ} \mathrm{C}$ and $5 \% \mathrm{CO}_{2}$ in air. All the cell lines first were maintained in RPMI 1640 with $10 \%$ FCS or with McCoy's 5A with $15 \%$ FCS, before being switched to culture in the serum-free medium. Cells were refed every 3 or 4 days by splitting the suspensions and adding fresh medium. At that time, cell counts were made and viability assessed by $0.2 \%$ trypan blue dye (GIBCO) exclusion, and by using a hemocytometer. The $32 \mathrm{Dcl} / \mathrm{H} 4$ that originally had been subcloned by Stadler to be more sensitive to human IL-3-like activity (18) was maintained in McCoy's 5A with $15 \%$ FCS and $10 \%$ conditioned medium (CM) derived from WEHI-3B (WEHI-3CM).

Factor production. Mo and WEHI-3B cells were incubated in serum-free or serumcontaining medium for 3-7 days, after which their supernatant fluids were harvested by centrifugation at $400 \mathrm{~g}$ for $15 \mathrm{~min}$ then filtered through a Millipore filter membrane after which they were stocked at $-20^{\circ} \mathrm{C}$ until use. CM was concentrated with a Diaflo PM10 membrane or a hollow fiber HIP10 (Amicon CORP., Danvers, MA).

IL-3 assay. An IL-3-dependent murine cell line, $32 \mathrm{Dcl} / \mathrm{H} 4$, was used to test the supernatant fluid for IL-3 activity as described by Stadler et al. (18). Briefly, samples to be tested for IL-3 like activity were diluted 2-fold in flat-bottomed, 96-well microtiter plates (3072 Falcon). $32 \mathrm{Dcl} / \mathrm{H} 4$ cells were washed in media, and $2 \times 10^{4}$ cells were added to each well. These cultures were PRMI1640 with $10 \%$ FCS incubated for $24 \mathrm{~h}$ at $37^{\circ} \mathrm{C}$ then pulsed 
for the final $6 \mathrm{~h}$ of incubation with $1 \mu \mathrm{Ci}\left[{ }^{3} \mathrm{H}\right]$ thymidine (methyl- ${ }^{3} \mathrm{H}$, specific activity $20 \mathrm{Ci} / \mathrm{mmol}$; New England Nuclear, Boston, MA) after which cells were harvested with an automatic harvester (Titertek, Flow Laboratories, McLean, VA) onto glass fiber filters, and the radioactivity was determined with a liquid scintillation counter (Beckman Instruments, Inc., Fullerton, CA) and is expressed as the arithmetic mean of the $\left[{ }^{3} \mathrm{H}\right]$ thymidine incorporated in duplicate cultures.

Colony stimulating factor (CSF) assay. CSF was assayed using the methylcellulose culture technique described previously (5). Briefly, $2 \times 10^{5}$ density gradient-separated mononuclear cells from cord blood from which adherent cells had been removed by incubation in plastic flasks for $1-2 \mathrm{~h}$ at $37^{\circ} \mathrm{C}$, were cultured in $0.9 \%$ methylcellulose containing IMDM, $20 \%$ FCS and $5 \times 10^{-5}$ M 2-mercaptoethanol (2ME) with, or without, $2.5-20 \%$ $\checkmark / v$ CM. Neutrophil-macrophage (GM)-type colonies and eosinophil (Eo)-type colonies containing $\geq 40$ cells were identified under an inverted microscope by their morphological appearance after 2 wk in vitro. Colonies were picked from the culture dishes by elongated Pasteur pipettes then placed on glass slides for histochemical staining.

Basophil/Eosinophil growth-promoting activity (BaGPA, EoGAP) assay. Non-adherent mononuclear cells from cord blood were cultured at a concentration of $1 \times 10^{6} \mathrm{cells} / \mathrm{ml}$ in McCoy's $5 \mathrm{~A}$ with $15 \%$ FCS and $5 \times 10^{-5} \mathrm{M} 2 \mathrm{ME}$ in 24 -well tissue culture plates (Limbro, Flow Laboratories) in the presence, or absence, of $\mathrm{CM}$ at $37^{\circ} \mathrm{C}$ in $5 \% \mathrm{CO}_{2}$ for $2 \mathrm{wk}$. Cell counts were made with a hemocytometer and cytochemical staining with May-GrunwaldGiemsa or $0.5 \%$ toluidine blue ( $\mathrm{pH}=0.5$, lead acetate fixative) on air-dried cytocentrifuged smears. The histamine content of the cultures was assayed by the automated fluorometric technique of Siraganian (16). Similar cultures have been shown to contain the peak number of basophils at $2 \mathrm{wk}$ and eosinophils at $4 \mathrm{wk}$ in vitro in the presence of Mo-CM (22).

\section{RESULTS}

Long term cell growth in serum-free medium, compared with serum-containing medium. The growth of Mo cells maintained in RITC 55-9 or in McCoy's 5A with $15 \%$ FCS for more than 8 months is shown in Fig. 1. The cultures were split once or

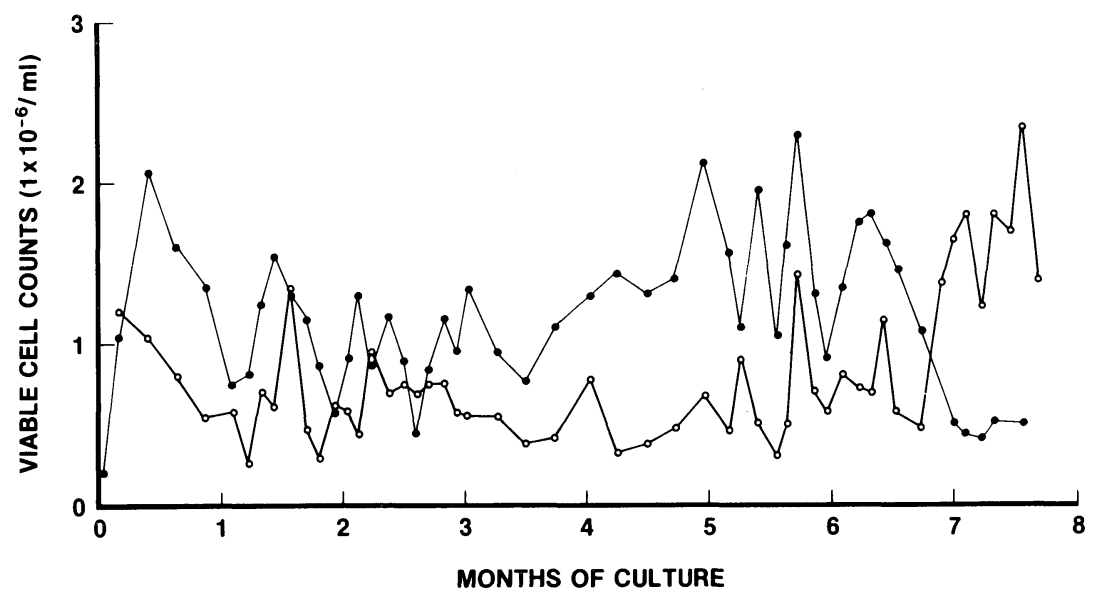

Fig. 1. Long term growth of Mo cells cultured in McCoy's 5A+15\% FCS (๑) and in RITC 55-9 (O). Cells were refed once or twice a week at a seeding density of $1-5 \times 10^{5} \mathrm{cells} / \mathrm{ml}$. 


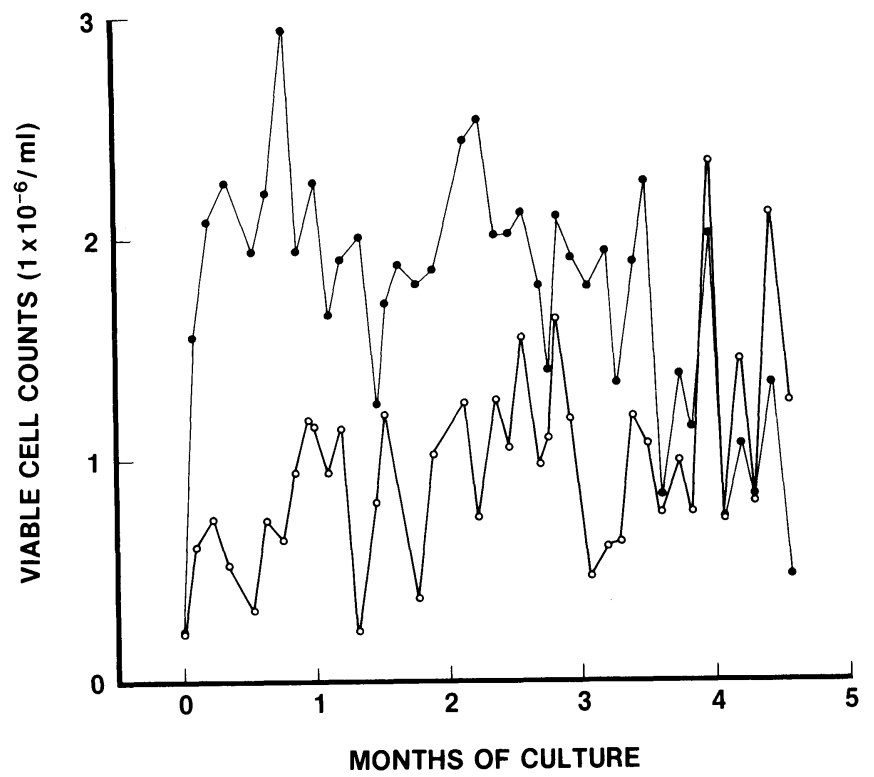

Fig. 2. Long growth of $32 \mathrm{Dcl} / \mathrm{H} 4$ cells cultured in McCoy's $5 \mathrm{~A}+15 \%$ FCS (๑) and in RITC 55-9 (O).

twice weekly to give a cell density of $1-5 \times 10^{5}$ cells $/ \mathrm{ml}$. During the first 6 months, both the cell count and viability of the serum-free cultures were lower than the values for the serum-containing cultures. After 7 months, the growth rate of the serum-free culture had improved to the point at which it was comparable to that of the serumcontaining culture. The overall mean viabilities of these serum-free and serumcontaining cultures were $59.4 \%$ and 79.5 . Frequent refeeding resulted in increased cell viability, providing the starting density was greater than $1 \times 10^{5} \mathrm{cells} / \mathrm{ml}$. The population doubling time of both cultures was almost the same (about $50 \mathrm{~h}$ ).

The growth curve of $32 \mathrm{Dcl} / \mathrm{H} 4$ cells cultured in RITC 55-9 or in McCoy's $5 \mathrm{~A}+$ $15 \%$ FCS in the presence of $10 \%$ WEHI-3 CM as shown in Fig. 2. During the first 3 months, there was a considerable difference in the growth rates of the two cultures, but after 4 months of culture, almost similar growth patterns were seen in both the serum-free and serum-containing cultures.

The WEHI-3B cells have survived in complete RITC 55-9 (i.e., supplemented with BSA, Tf and Ins) as well as in RITC 55-9 without Tf and Ins, whereas the protein-free cultured WEHI-3B cells died after 3 months of culture (Fig. 3). Our WEHI-3B cells have been growing well for more than 24 months in complete RITC 55-9. Cells cultured both in complete RITC 55-9 and in RITC 55-9 without Tf and Ins had doubling times of $20 \mathrm{~h}$. Cells maintained in protein-free RITC showed a 2 -fold increase in this doubling time.

Factor production by cell lines growing in serum-free medium. The production of CSF and BaGPA by Mo cells grown for 7 days in RITC or McCoy's $5 \mathrm{~A}+15 \%$ FCS was examined. Mo cells produced amounts of CSF in serum-free medium similar to those produced in serum containing medium (Fig. 4), but larger amounts of BaGPA and EoGPA were produced by Mo cells cultured in serum-free medium (Fig. 5). 


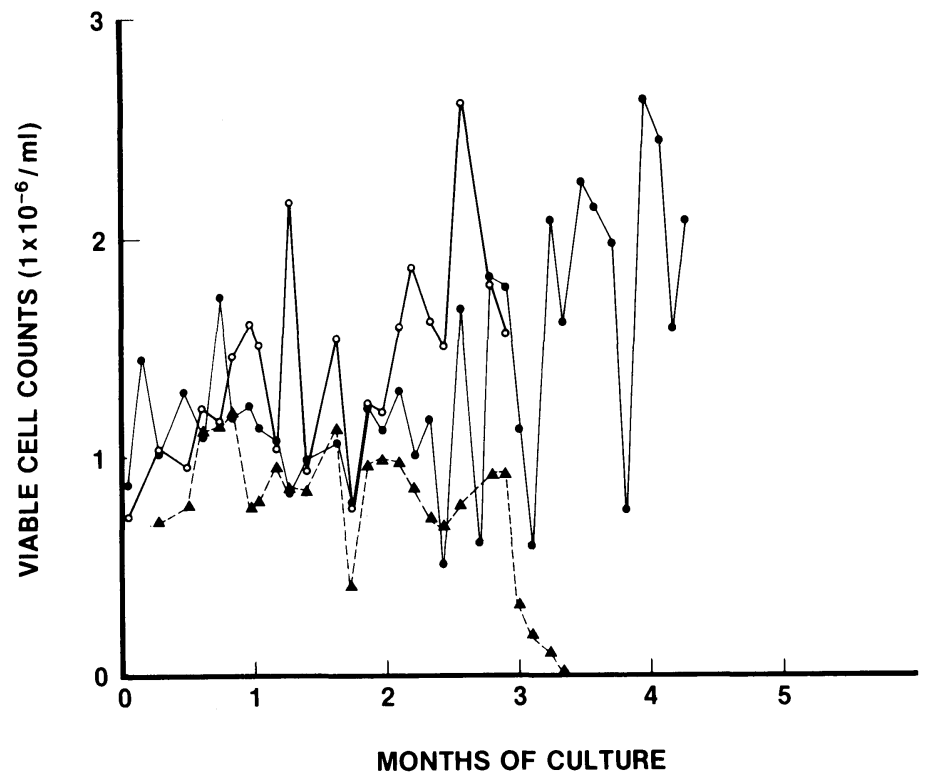

Fig. 3. Long term growth of WEHI-3B cells cultured in complete RITC 55-9 (๑), in RITC 55-9 without Tf and Ins $(O)$ and in protein-free RITC 55-9 (A). Cells that were cultured in proteinfree medium only did not survive.

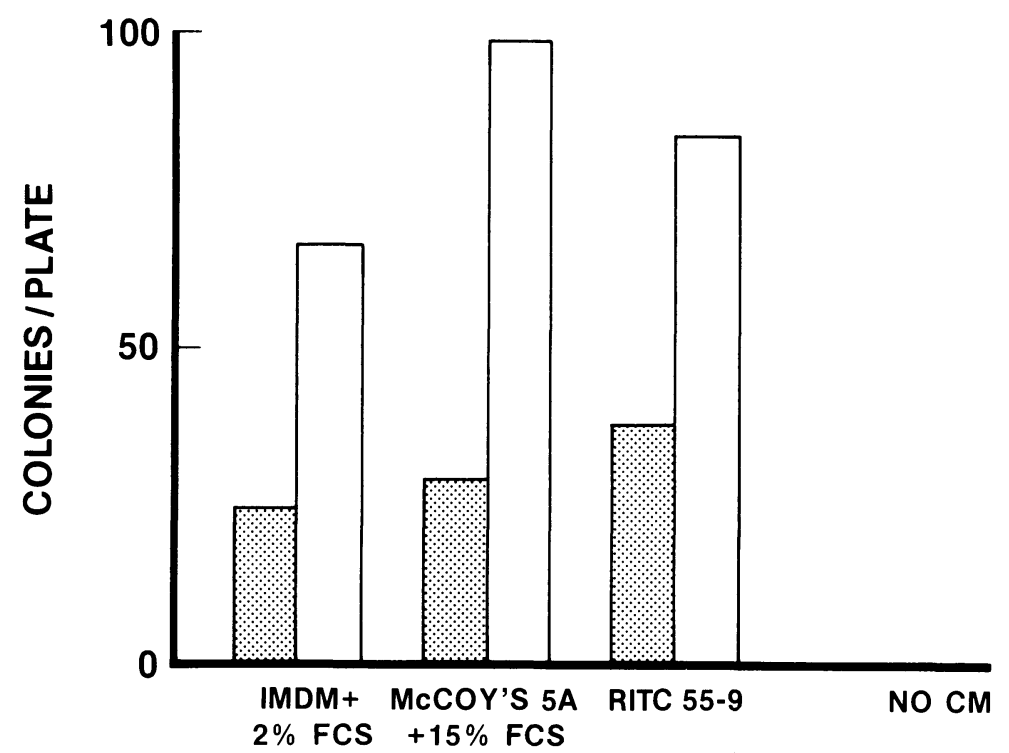

Fig. 4. CSF activities of MoCMs derived from Mo cells cultured in McCoy's $5 \mathrm{~A}+15 \% \mathrm{FCS}$, IMDM $+2 \%$ FCS and RITC 55-9. CMs were harvested from 7-day-old cultures. $4 \times 10^{5}$ mononuclear cells from cord blood were cultured in methylcellulose-containing IMDM $+20 \%$ FCS for 14 days with or without, CM. ․ㅏㅇ, Eo-type colony; $\square$, GM-type colony. 


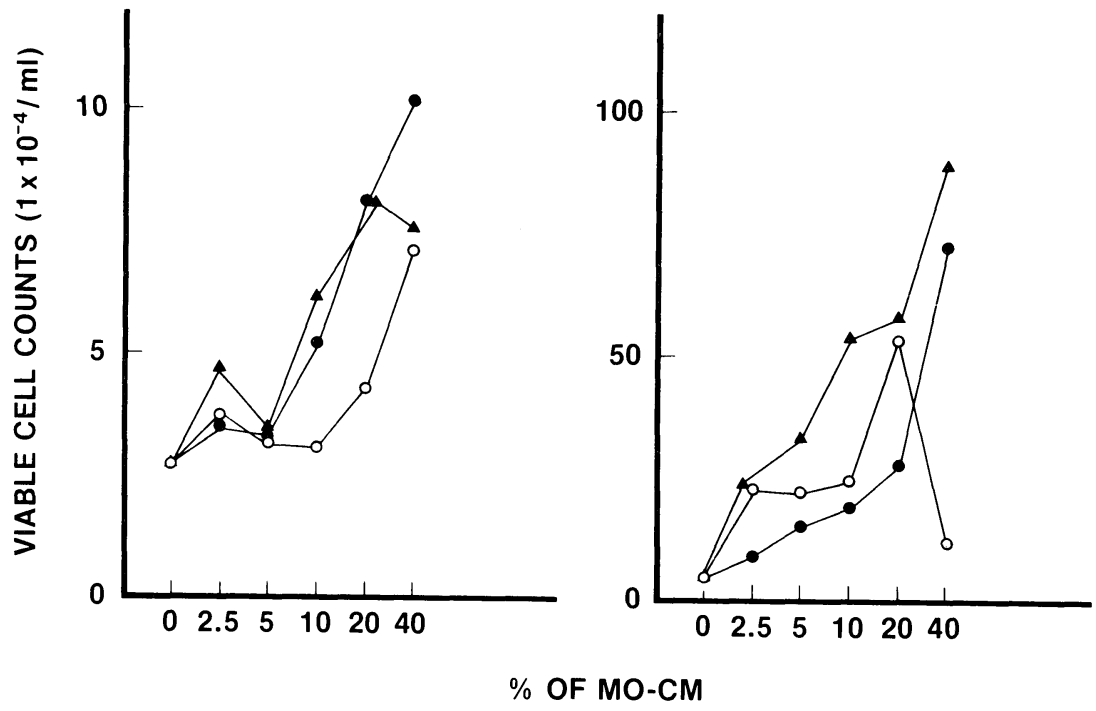

Fig. 5. BaGPA/EoGPA of Mo CMs derived from Mo cells cultured in IMDM $+2 \%$ FCS (๑) in McCoy's 5A+15\% FCS $(\bigcirc)$ and in RITC 55-9 (A). CMs were harvested from 7 day-old cultures. $1 \times 10^{6} / \mathrm{ml}$ mononuclear cells from cord blood were cultured in McCoy's $5 \mathrm{~A}+15 \%$ FCS for 14 days without CM.

The production of IL-3 by WEHI-3B cells also was examined in various media. Larger amounts of IL-3 were present under serum-free conditions in all the media tested (Fig. 6).

Responsiveness of $32 \mathrm{Dcl} / \mathrm{H} 4$ cells grown in RITC $55-9$ to $I L-3 . \quad 32 \mathrm{Dcl} / \mathrm{H} 4$ cells maintained in RITC 55-9 became responsive to IL-3 one month after being switched from culture in serum-containing medium to culture in serum-free medium. There was a higher responsiveness than found in the reaction of $32 \mathrm{Dcl} / \mathrm{H} 4$ cultured in McCoy's $5 \mathrm{~A}+15 \% \mathrm{FCS}$ to WEHI-3B CM. The responsiveness of these serum-free cultured $32 \mathrm{Dcl} / \mathrm{H} 4$ cells to IL-3 had decreased to approximately half the value found for cells cultured in serum three months after their transfer to serum-free conditions. Lower responsiveness also was found when RITC 55-9 was used in the IL-3 assay system for human materials instead of McCoy's $5 \mathrm{~A}+15 \%$ FCS (data not shown).

\section{DISCUSSION}

We here have shown the successful long-term culture of a human $\mathrm{T}$ lymphocyte leukemia cell line, Mo, a mouse myelomonocytic cell line, WEHI-3B and the mouse IL-3 dependent cell line, 32Dcl/H4 in a serum-free medium, RITC 55-9. Under our experimental conditions, Mo and WEHI-3B cells had similar or higher production of hemopoietic growth factors than cultures of the same type cells in serum-containing medium. Previously, Uittenbogaart et al. (24) reported failure to maintain long-term, serum-free cultures of Mo cells, which may have been due to the use of different supplements in the serum-free medium: They used delipidated BSA and did not add lipids and insulin. Lipids in particular, appear to be essential for the growth of Mo cell because we previously demonstrated the essential role of albumin-bound 


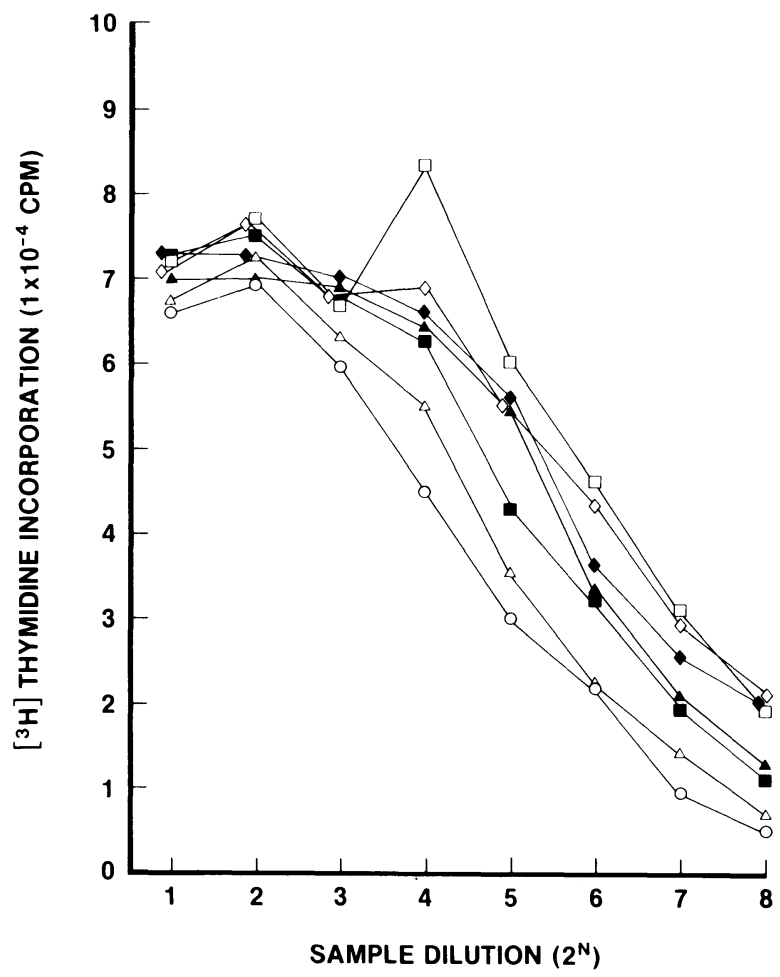

Fig. 6. IL-3 activity of WEHI-3B CMs derived from WEHI-3B cells cultured in RPMI $1640+1 \%$ FCS $(\bigcirc)$, in McCoy's $5 A+15 \%$ FCS $(\triangle)$, in IMDM $+0.5 \%$ BSA $(\square)$, in protein-free IMDM $(\square)$, in complete RITC 55-9 (A), in RITC 55-9 without transferrin and insulin $(\diamond)$ and in protein-free RITC 55-9 ( ). CMs were harvested from 3-day-old cultures. $32 \mathrm{Dcl} / \mathrm{H} 4$ cells were cultured in McCoy's $5 \mathrm{~A}+15 \% \mathrm{CS}$ with or without, serially 2-fold-diluted CMs for $24 \mathrm{~h}$.

lipids in human T lymphocyte growth (1). Cohn frantion V BSA recently has been reported to be required for mouse erythropoietic burst production in vitro (19) and the same authors speculated that Cohn fraction V BSA might facilitate the production of burst-promoting activity by bone marrow T cells (19). Therefore, Mo cells may require some substances associated with BSA, as well as the protein itself, for long term culture. BSA as well as $\mathrm{Na}_{2} \mathrm{SeO}_{3}$ (which was included in RITC 55-9) has been shown to function in the elimination of $\mathrm{H}_{2} \mathrm{O}_{2}$ or some reactive radical cytotoxic to human lymphoid cells (4).

Because various cell types require different concentrations different nutritional additives or both, for optimal growth or function $(3,24)$, it is not unusual that the 32Dcl/H4 cells maintained in RITC 55-9 had lower responses to IL-3. For example, Honma et al. (9) showed that although mouse myeloid leukemia cells (M1) could grow in synthetic medium supplemented with Tf, Ins and trace elements, differentiation could not be induced by dexamethasone without the presence of albumin, phosphatidyl choline and cholesterol. They also reported that although differentiation was induced in sensitive cells grown in serum-free medium for several days, the same cells cultured in serum-free medium for a long period did not differentiate (9). We found a similar change in responsiveness to IL-3 for $32 \mathrm{Dcl} / \mathrm{H} 4$ cells cultured in 
serum-free medium. Also Taetle et al. reported that when a human promyelocytic leukemia cell line, HL60, was cultured in serum-free medium, it was less likely to be induced to differentiate by dimethyl sulfoxide (20). Altered function or a different antigenic or receptor density expressed by cells grown in serum-free medium may be the source of these differences.

Our goal is to develop a fully chemically defined medium that supports cell growth and factor production. Our RITC 55-9 is not fully defined because the ingredients used have not been purified to homogeneity. Although a protein-free medium is an ideal serum-free medium, its applicability is limited except with a few cell lines (14). Our protein-free culture of WEHI-3B failed within 3 months, but other cell lines may prove more easier to grow under protein-free conditions. Serum-free culture should provide an excellent system for the analysis and understanding of the biological roles of growth and differentation factors and for the purification of these factors without interference from unknown serum components.

Acknowledgements. This research was supported by grants from the National Cancer Institute and Medical Research Council of Canada. Y.T. was a Postdoctoral Fellow of McMaster University in Canada, supported by Pharmacia Diagnostics, Uppsala, Sweden.

\section{REFERENCES}

1. Arai, S., I. Yamane, Y. Tanno, and T. Takishima. Role of bovine serum albumin in blastoid transformation of lymphocytes by phytohemagglutinin. Proc. Soc. Exp. Biol. Med., 154, 444-448, 1977

2. Breitman, T.R., S.J. Collins, and B.R. KeEne. Replacement of serum by insulin and transferrin supports growth and differentiation of human promyelocytic cell line, HL-60. Exp. Cell Res., 126, 494-498, 1980

3. Brown, R.L., R.L. Griffith, R.H. Neubauer and H. Rabin. Development of a serum-free medium which supports long-term growth of human and non-human primate lymphoid cells.

J. Cell. Physiol., 115, 191-198, 1983

4. DARfler, F.J. and P.A. InSEl. Clonal growth of lymphoid cells in serum-free media requires elimination of $\mathrm{H}_{2} \mathrm{O}_{2}$ toxicity. J. Cell. Physiol., 115, 31-36, 1983

5. Denburg, J.A., M. Richardson, S. Telizyn, and J. Bienenstock. Basophil/mast cell precursors in human peripheral blood. Blood, 61, 775-780, 1983

6. Eliason, J.F. and N. Odartchenko. Colony formation by primitive hemopoietic progenitor cells in serum-free medium. Proc. Natl. Acad. Sci. U.S.A., 82, 775-779, 1985

7. Golde, D.W., S.G. QuAN, and M.J. Cline. Human T lymphocyte cell line producing colonystimulating activity. Blood, 52, 1068-1072, 1978

8. Gospodarowicz, D. and J.S. Moran. Growth factors in mammalian cell culture. Ann. Rev. Biochem., 45, 531-558, 1976

9. Honma, Y., T. Kasukabe, J. Okabe, and M. Hozumi. Replacement of serum by insulin, transferrin, albumin, phosphatidyl choline, cholesterol and some trace elements in cultures of mouse myeloid leukemia cells sensitive to inducers of differentiation. Exp. Cell Res., 124, $421-428,1979$

10. Iscove, N.N., L.J. Guilbert, and C. Weyman. Complete replacement of serum in primary cultures of erythropoietin-dependent red cell precursors (CFU-E) by albumin, transferrin, iron, unsaturated fatty acid, lecithin and cholesterol. Exp. Cell Res., 126, 121-126, 1980

11. Iscove, N.N. and F. Melchers. Complete replacement of serum by albumin, transferrin and soybean lipid in cultures of lipopolysaccharide-reactive B lymphocytes. J. Exp. Med., 147, 923-933, 1978

12. Kubota, K., K. Motoyoshi, S. Kajigaya, T. Suda, M. Saito, and Y. Miura. Morphological examinations of murine granulocyte/macrophage colonies grown in serum-free cultures. 
Exp. Hematol., 11, 364-370, 1983

13. Mosier, D.E. Primary in vitro antibody responses by purified murine B lymphocytes in serum-free defined medium. J. Immunol., 127, 1490-1493, 1981

14. OKabe, T., M. Fujisawa and F. TAKaKu. Long-term cultivation and differentiation of human erythroleukemia cells in a protein-free chemically defined medium. Proc. Natl. Acad. Sci. U.S.A., 81, 453-455, 1984

15. SChmit, S. and H.A. SChenkein. Lymphokine production and lymphocyte transformation by human mononuclear cells in a serum-free medium. J. Immunol. Methods, 63, 337-345, 1983

16. Siraganian, R.P. An automated continuous flow system for the extraction and fluorometric analysis of histamine. Anal. Biochem., 57, 383-394, 1974

17. Spits, H., H. IJsSEl, C. Terhorst, and J.E. DeVries. Establishment of human T lymphocyte clones highly cytotoxic for an EBV-transformed B cell line in serum-free medium: Isolation of clones that differ in phenotype and specificity. J. Immunol., 128, 95-99, 1982

18. Stadler, B.M., K. Hirai, K. Tadokoro, and A.L.De. Weck. Distinction of the human basophil promoting activity from human interleukin-3 Int. Archs. Allergy Appl. Immunol., 77, 151-154, 1985

19. Stewart, S., B. Zhu, and A. Axelrad. A "serum-free" medium for the production of erythropoietic burst by murine bone marrow cell. Exp. Hematol., 12, 309-318, 1984

20. Taetle, R., K. Rhyner, J. Castagnda, D. To, and J. Mendelsohn. Role of transferrin, $\mathrm{Fe}$ and transferrin receptors in myeloid leukemia cell growth. Studies with an antitransferrin receptor monoclonal antibody. J. Clin. Invest., 75, 1061-1067, 1985

21. TANNO, Y., S. AraI, and T. TAKishima. Induction of immunoglobulin-producing human peripheral blood lymphocytes in serum-free medium. J. Immunol. Methods, 52, 255-265, 1982

22. Tanno, Y., J.A. Denburg, and J. Bienenstock. Human basophil and eosinophil growth in long-term cord blood cultures. Fed. Proc., 43, 1935, 1985

23. Titeux, M., U. Testa, F. Louache, P. Thomopoulos, H. Rochant, and J. Breton-Gorius. The role of iron in the growth of human leukemic cell lines. J. Cell. Physiol., 121, 251-256, 1984

24. UittenbogaART, C.H., Y. Cantor, and J.L. Fahey. Growth of human malignant lymphoid cell lines in serum-free medium. In Vitro, 19, 67-72, 1983

25. Warner, N.L., M.A.S. Moore, and D. Metcalf. A transplantable myelomonocytic leukemia in BALB/c mice: Cytology, karyotype and muramidase content. J. Natl. Cancer Ins., 43, 963-982, 1969 